\title{
Acoustic Emission Sensing of Pipe-Soil Interaction: Full-scale Pipelines Subjected to Differential Ground Movements
}

\author{
Alister Smith, Ph.D. ${ }^{1 *}$; lan D. Moore, Ph.D., M.ASCE²; and Neil Dixon, Ph.D. ${ }^{3}$
}

${ }^{1}$ EPSRC Fellow and Lecturer in Civil Engineering Infrastructure, School of Architecture, Building and Civil Engineering, Loughborough University, Leicestershire, UK, LE11 3TU (corresponding author). *E-mail: A.Smith10@lboro.ac.uk

2 Professor and Canada Research Chair in Infrastructure Engineering, GeoEngineering Centre at Queen's—RMC, Queen's University, Kingston, ON, Canada K7L 3N6

${ }^{3}$ Professor of Geotechnical Engineering, School of Architecture, Building and Civil Engineering, Loughborough University, Leicestershire, UK, LE11 3TU 


\section{Abstract}

This paper presents the first full-scale demonstration of the potential use of pipe/soil interaction-generated acoustic emission (AE) for early detection of buried pipe deformation. Full-scale tests were performed at the buried infrastructure research facility at Queen's University, Canada, using a split-box apparatus to impose differential ground motion on a steel pipe buried in dry sand, and to investigate the influence of stress level and patterns of deformation on $\mathrm{AE}$ generation. The pipe was instrumented with $\mathrm{AE}$ sensors, strain gauges, fibre optic strain sensing and linear potentiometers, and surface deformation was measured using an automatic total station. AE measurements were used to interpret the evolution of the pipe/soil interaction behaviour. AE activity correlated strongly ( $R^{2}$ from 0.83 to 0.99 ) with both the rate and magnitude of pipe deformation at different burial depths, and quantified relationships are presented that enable interpretation of pipe/soil interaction behavior from AE measurements.

\section{Keywords}

Acoustic Emission; Buried pipelines; Deformation; Ground movements; Monitoring; Soilstructure interaction 


\section{Introduction}

Pipeline networks cover vast geographical areas to transport water, oil and gas, and hence are critical lifelines upon which society heavily relies. A significant proportion of these assets are buried in soil for protection and support; however, this exposes them to potential damage from ground movements. Buried pipelines experience significant strains in response to large soil shearing deformations (e.g. faulting, landslides and differential settlement), which can lead to tensile or buckling failure. Localised pipeline damage can have catastrophic economic, environmental and societal consequences, and the service of entire networks can be terminated (Karamitros et al. 2007; Vazouras et al. 2015; Robert et al. 2016). There is an urgent need for continuous, remote, real-time monitoring strategies that can be retrofitted to existing assets to provide early warning of this behavior and enable targeted and timely interventions.

Proportions of the energy dissipated during deformation of particle materials are converted to heat and sound. The high-frequency $(>10 \mathrm{kHz})$ component of this sound energy is called Acoustic Emission ( $\mathrm{AE}$ ), which propagates through materials surrounding the generation source. AE is generated in soil/structure systems through a suite of mechanisms including: inter-particle friction (rolling and sliding); friction at the interface between the soil and structural element; force chain buckling (e.g. slip-stick behaviour as interlock is overcome and regained) of particle assemblies; and degradation of particle asperities (Smith et al. 2014; Heather-Smith et al. 2018). Fundamental laboratory studies on the AE behavior of soils were carried out in the 1970s, 1980s and 1990s (e.g. Koerner et al. 1976; Koerner et al. 1978; Koerner et al. 1981; Koerner et al. 1984; Mitchell and Romeril 1984; Tanimoto and Tanaka 1986; Garga and Chichibu 1990; Shiotani and Ohtsu 1999). Recent advances have been made in the interpretation of soil/structure interaction behavior from AE measurements using physical modelling and field experiments for slope instability (Smith et al. 2014; Smith and Dixon 2015; Dixon et al. 2015a; Dixon et al. 2015b; Michlmayr et al. 2017; Smith et al. 2017a; Berg et al. 2018; Dixon et al. 2018) and pile loading (Mao et al. 2015; Mao et al. 2016; Mao et al. 2018) applications.

Research has developed an AE landslide early warning system, named Slope ALARMS, which is able to provide early detection of progressive failure and quantify displacement rates ranging from $0.0001 \mathrm{~mm} /$ hour to more than $400 \mathrm{~mm} /$ hour, as evidenced by field trials and large-scale laboratory testing (Smith et al. 2014; Smith and Dixon 2015; Dixon et al. 2015a; Dixon et al. 2015b; Smith et al. 2017a; Berg et al. 2018; Dixon et al. 2018). Moreover, Smith \& Dixon (2019) demonstrated the benefits of using AE to monitor the behaviour of dense sands in triaxial experiments, and they proposed a framework to interpret the mobilisation of peak shear strength and to quantify rates of shear strain from AE measurements.

The objective of this study was to investigate the potential use of $A E$ to detect and measure pipe/soil interaction behavior. This work formed part of the Listening to Infrastructure project, which aims to develop AE technologies that can be retrofitted to geotechnical infrastructure assets. The study findings have significant implications for the development of a continuous, real-time AE monitoring system that can be distributed at discrete locations along buried pipes to sense pipe/soil interaction resulting from a range of deformation mechanisms and provide early warning that will enable targeted and timely interventions. Nascent technologies, such as fibre optics, are beginning to provide valuable pipe asset health monitoring information; however, retrofitting hundreds of thousands of kilometres of assets with these sensors would be prohibitively intrusive and expensive. The advantage of the AE approach is that sensors could be installed at discrete locations, for example at spacings of hundreds of metres (Smith et al. 2017b), to 
provide high spatial and temporal resolution information for use in early warning of adverse deformation behaviour.

This paper describes experiments that were performed at the buried infrastructure research facility at Queen's University, Canada, using a split-box apparatus that allows differential ground motion to be applied to buried pipes (e.g. Ni et al. 2017). These normal faulting (dip angle of $90^{\circ}$ ) experiments were used to simulate differential ground motion on buried pipelines with a known and controlled deformation regime; however, it should be noted that the normal fault testing is a proxy for many other sources and patterns of differential ground movements.

Two of these normal faulting (dip angle of $90^{\circ}$ ) tests were performed on a steel pipe with different burial and bedding (i.e. foundation) depths, and varying rates of deformation were imposed to investigate the $A E$ response to accelerating deformation behaviour that accompanies progressive failure processes. AE measured from two different systems connected to the pipe was compared with pipe and soil behaviour measured using a suite of other instrumentation and monitoring techniques. The findings from the research reported here demonstrate that $A E$ can be used to detect, quantify and interpret accelerating differential ground motion deforming buried pipelines.

\section{Methodology}

\section{Apparatus and Testing Considerations}

A schematic of the apparatus is shown in Figure 1, which was originally developed to simulate normal faulting with a dip angle of $90^{\circ}$. The differential ground movement apparatus enables half of the soil block (above the moving floor) to displace downwards relative to the other (Figure $2 \mathrm{a}$ ).

Two tests were performed on the same steel pipe but at different burial and bedding depths. Test 1 was performed with $0.6 \mathrm{~m}$ burial (1.2 $\mathrm{m}$ foundation) and Test 2 with $1.2 \mathrm{~m}$ burial ( $0.5 \mathrm{~m}$ foundation). This allowed investigation of the influence of stress level and bedding depth on the pipe/soil interaction and generated AE. The two burial depths were selected to fall within the typical range for gas pipes (Groves and Wijewickreme 2013).

When post-peak shear strength is mobilised in soils, accelerating deformation behaviour typically occurs as the same boundary stresses are applied to the system. The influence of deformation rate on pipe/soil interaction-generated $A E$ was a focus of this study and so varying displacement rates were applied; the average deformation rate imposed in each test stage is shown in Table 1. Floor displacement was controlled by manually operated drive shafts, which limited the range of displacement rates that could be applied. The influence of varying the rate of displacement on the magnitude and locations of peak strains in the pipe has been proven to be insignificant (Abdoun et al. 2009; Ni et al. 2017). Each test stage comprised a $10 \mathrm{~mm}$ increment of displacement: eight increments were applied in Test 1 (80 mm total displacement) and 10 were applied in Test 2 (100 $\mathrm{mm}$ total displacement).

Figure 1c shows the positions of installed strain gauges (SG) on the pipe crown and invert. The results from Test 1 showed that the point of contraflexure moved outside of the SG measurement zone as uplift failure occurred during the test, which motivated the installation of fibre optic (FO) distributed strain sensing on the crown and invert in preparation for Test 2 . The pipe section was rotated by $30^{\circ}$ to achieve this as shown in Figure 1d. 


\section{Backfill and Pipe Selection}

The backfill used in the experiments was synthetic olivine sand (used in commercial sand blasting), which has higher particle density than conventional silica sands, enabling reuse in multiple tests as it is resilient to crushing and degradation (Ni et al. 2017). The properties of olivine sand are shown in Table 2.

A steel pipe was selected for this study for two key reasons: (1) steel pipelines are the most common choice for transporting water, oil and gas across large geographic areas and hence are likely to intersect a range of geohazards; and (2) AE propagates long distances in steel with minimal attenuation $(<0.2 \mathrm{~dB} / \mathrm{m})$ (Smith et al. 2017b).

\section{Imposed Behavior}

At the onset of floor displacement, a displacement discontinuity develops at the interface between the moving and stationary floor, generating a highly concentrated shear zone within the soil. With further increments of displacement, this shear zone propagates upwards through the soil body, spreading out so that the shear strains become less localised at the surface (Figure 2a). The distribution of shear strains across the shear band with depth can be characterised by the parameter $i_{\text {soil, }}$ which is the distance between the point of contraflexure (at or near the concentrated shear zone) to the position of peak curvature along the soil deflection profile. Hence, $i_{\text {soil }}$ increases towards the surface, and through numerical analysis has been found to be a function of bedding (i.e. foundation) depth, $B$ (Equation 1) (Ni et al. 2014; Ni et al. 2017; Ni et al. 2018).

$i_{\text {soil }}=0.18 \mathrm{~B}$

The response of a pipeline buried inside the soil body is dominated by bending and the pipe/soil interaction is governed by the relative pipe/soil stiffness. On the stationary (footwall) side, the pipe experiences a hogging deflection and compresses the soil beneath, and resistance here is controlled by the soil's bearing capacity. On the moving (hanging wall) side, the pipe experiences a sagging deflection and resistance here is controlled by the soil's uplift capacity. Peak bending moments develop in the hogging zone because the soil's bearing capacity is significantly greater than its uplift capacity (Bransby et al. 2007; Anastasopoulos et al. 2007; Saiyar et al. 2016; Ni et al. 2018). A critical value that may be used in design is $i_{p i p e}$, which is the distance between the position of peak curvature to the point of contraflexure along the pipe's deflection profile. Relative pipe/soil stiffness influences $i_{\text {pipe }}$ and it has been observed to increase with displacement as postpeak soil shear strength (i.e. reduced stiffness) is gradually mobilised along the length of the pipe (Bransby et al. 2007; Ni et al. 2018). High stiffness pipes (e.g. steel) act to spread out the flexural response across the shear zone by a bridging mechanism ( $\left.i_{\text {pipe }} / i_{\text {soil }}>1.0\right)$.

The uplift soil failure mechanism in the pipe sagging zone comprises four key stages (Figures 2b and 2c) (Cheuk et al. 2008): (1) mobilisation of peak resistance; (2) gap formation beneath the pipe invert and infilling; (3) post-peak shear band formation; and (4) flow-around soil displacement. The magnitude of reaction force exerted on the pipe by the soil depends on the magnitude of relative pipe/soil displacement, and greater displacements are required to mobilise peak shear strength under greater burial depths. A gap with sloping sides forms beneath the pipe during mobilisation of peak uplift resistance. These slopes then fail and infill the gap beneath the pipe. Shear strain concentrates into a pair of dilating shear bands, which initiate at the springlines and curve outwards and widen as they propagate to the surface. A flow-around mechanism is formed accompanied by a reduction in the uplift resistance due to post-peak shear band formation. The failure 
mechanism resembles an inverted trapezoidal block (Bransby et al. 2007; Cheuk et al. 2008).

\section{Pipe Length Determination}

The free pipe ends introduce boundary conditions that are not representative of the real in situ case. The subgrade reaction method (Bransby et al. 2007; Ni et al. 2017) (Equations 2 to 5) was used to calculate the critical pipe length, $I_{c}$, beyond which the pipe behaves as if it is infinitely long (fully flexible). $l_{c}$ was used to select a pipe length $(6.5 \mathrm{~m}$ as shown in Figure 1) that minimised pipe end boundary effects. The computed parameters are shown in Table 3.

$I_{C}=4\left(\frac{E_{\mathrm{p}} I_{\mathrm{p}}}{k_{\mathrm{u}}}\right)^{0.25}$

$Q_{u}=\gamma H\left(1+f_{\mathrm{d}} \frac{H}{D}\right)$

$k_{\mathrm{u}}=\frac{Q_{\mathrm{u}}}{\Delta q_{\mathrm{u}}}$

$\Delta q_{\mathrm{u}}=0.02 H$

where $E_{\mathrm{p}} / \mathrm{p}$ is the pipe's flexural rigidity, $k_{u}$ is the soil's reaction stiffness, $Q_{u}$ is the soil's peak uplift resistance, $\Delta q_{\mathrm{u}}$ is the displacement required to mobilise peak uplift resistance in dense sand, $y$ is the unit weight of soil, $H$ is the burial depth to the springline, $D$ is the pipe's outside diameter, and $f_{\mathrm{d}}$ is the uplift factor, which is 1.0 for dense sand (Bransby et al. 2007; Ni et al. 2017).

\section{Displacement and Strain Instrumentation}

A linear (string) potentiometer (LP) was connected at $20 \mathrm{~cm}$ from the pipe end to measure vertical pipe displacement (as shown in Figure 1a). Another LP was connected to the moving floor to measure floor displacement. The positions of the installed SGs (Showa N11-FA-5-120-11 uniaxial type, $5 \mathrm{~mm}$ gauge length, measuring accuracy of 10 microstrain) are shown in Figure 1c, and they were selected based on estimations of the positions of peak bending. For Test 2 , the pipe section was rotated $30^{\circ}$ as shown in Figure $1 \mathrm{~d}$ to enable installation of $\mathrm{FO}$ distributed strain sensors along the crown and invert. The FO analysis used an optical backscatter reflectometer (OBR) 4600 system from Luna Technologies and a gauge length of $20 \mathrm{~mm}$. Deformation of the soil surface was measured throughout both tests using automatic total station monitoring of an array of targets.

\section{Acoustic Emission Instrumentation}

Two AE sensors were coupled to the inside wall of the pipe, $20 \mathrm{~cm}$ from the pipe end on the moving side, using magnetic holders, with a layer of silicone gel to improve transmission of the stress waves propagating in the pipe wall. Both sensors were MISTRAS R3a piezoelectric transducers, which are sensitive over the frequency range of $0-100 \mathrm{kHz}$ and have a resonant frequency of $30 \mathrm{kHz}$. The sensors convert the mechanical $A E$ to a voltage waveform that can be processed. Each sensor was connected to a different AE measurement system.

AE system (1) was a device developed for field monitoring of slopes, named Slope ALARMS (e.g. Smith et al. 2014; Smith and Dixon 2015; Dixon et al. 2015a; Dixon et al. 2015b; Smith et al. 2017a; Berg et al. 2018; Dixon et al. 2018), and comprised a bandpass filter to attenuate signals outside of the $20-30 \mathrm{kHz}$ range and amplification of $70 \mathrm{~dB}$ to 
improve the signal-to-noise ratio. Focusing AE measurement to within $20-30 \mathrm{kHz}$ removes environmental noise (e.g. construction activity and traffic). This system measures ringdown counts (RDC) per unit time, which are the number of times the AE waveform crosses a programmable threshold level (set to $0.25 \mathrm{~V}$ ) within a predefined time interval and are a measure of the signal energy.

AE system (2) was a bespoke setup comprising a pre-amplifier (with a 10-1200 kHz filter and $20 \mathrm{~dB}$ amplification) a main amplifier (with a 10-100 kHz filter and $3 \mathrm{~dB}$ amplification), an analogue-to-digital converter with $2 \mathrm{MHz}$ sampling frequency, and a laptop with a LabView program to condition, process and record the AE waveform. The two amplifiers were used to improve the signal-to-noise ratio. The LabView program was set to further attenuate signals outside of the $10-100 \mathrm{kHz}$ range and record the full $A E$ waveform within this frequency range, enabling detailed investigation of the $A E$ and over a wider frequency range than $\mathrm{AE}$ system (1).

A key AE parameter of interest that can be obtained from the full $A E$ waveform data is the $b$-value (Pollock 1973), which is a convenient way to describe the amplitude distribution in a single value. The $b$-value was computed at one-minute intervals using Equations 6 and 7.

$\log N=c-b M$

$M=\log A$

where $A$ is the amplitude, $M$ is a log-scale measure termed magnitude, $N$ is the number of $\mathrm{AE}$ events with magnitude greater than $M, c$ is the point that the $\log (N)$ vs. $M$ relationship intersects the y-axis, and the coefficient $b(b$-value) is the negative slope of the $\log (N)$ vs. $M$ relationship.

When the AE waveform is dominated by low amplitude events the $b$-value is large. As the proportion of higher amplitude events increases, indicating an increase in energy, the $b$ value reduces.

\section{Test Preparation}

The test setup followed a comparable procedure to that described in Ni et al. (2017). The side and end walls of the empty test box were first covered with friction treatment to reduce mobilised shear stress at the soil/wall interface. The friction treatment comprised a base layer of polyethylene sheet, which was fixed in position at the top of the walls. This was coated in a thin film of silicone-based bearing grease to act as a lubricant, and then a second layer of polyethylene sheet was placed on top. The second sheet slides against the base sheet during the test, mobilising a peak angle of friction of less than $5^{\circ}$ (Tognon et al. 1999).

Dry sand backfill was placed using an overhead hopper and compacted in $150 \mathrm{~mm}$ lifts using a vibrating plate compactor (Wacker WP1550AW), achieving an average dry density of $1.67 \mathrm{Mg} / \mathrm{m}^{3}$ (measured using density cups at three locations in each lift), which corresponds to the target relative density, $D_{\mathrm{r}}$, of $85 \%$. The pipe was placed at the target elevation (bedding depth), with plastic caps covering the pipe ends to prevent soil infilling the pipe and to minimise $A E$ generation at the pipe ends. AE generation around the circumference of the pipe was the focus of this investigation, which is representative of the in situ continuous pipe case. All cabling was routed up the end wall on the moving side. Backfilling and compaction then continued in $150 \mathrm{~mm}$ lifts to achieve the target burial depth. 


\section{Results}

\section{Pipe and Soil Behavior}

The imposed floor movement and measured vertical downwards pipe displacement time series are shown in Figure 3. Pipe displacement closely followed the floor movement throughout both tests, with the pipe displacement deviating slightly and reaching a total displacement approximately $1 \mathrm{~mm}$ greater than the floor movement. It is unclear how pipe displacement could exceed floor movement; the discrepancies could be due to axial pipe displacement causing the string potentiometer connected to the pipe to measure a displacement vector combining both vertical and horizontal components.

The longitudinal strains measured by the SGs on the crown and invert at the end of stages 1 and 8 in Test 1 are shown in Figure 4. The point of contraflexure (i.e. crown and invert strain are zero) can be interpreted from the measurements on the moving side after stage 1 ; however, with further increments of displacement, the point of contraflexure moves further away from the displacement discontinuity and outside of the SG zone (i.e. $i_{\text {ipe }}$ increases with displacement). The FO and SG strain measurements from Test 2 are shown in Figure 5 . The fluctuations in longitudinal strain at the position of peak bending are thought to be due to issues with the bond between the FO and pipe.

At the end of stage 1 , the value of $i_{\text {pipe }}$ (hogging) was $1.1 \mathrm{~m}$ and $0.9 \mathrm{~m}$ in Test 1 and Test 2 , respectively, and the corresponding $i_{\text {pipe }}$ (hogging) / $i_{\text {soil }}$ ratios were 5.1 and 10.0. The more concentrated shear strains and greater stress level at the pipe elevation in Test 2 led to a narrower pipe bending zone (smaller $i_{\text {pipe }}$ ). Figure 6 shows the evolution of the hogging and sagging $i_{\text {pipe }} / i_{\text {soil }}$ ratios for Test 2 . It is notable that $i_{\text {pipe }}$ (sagging) $/ i_{\text {soil }}$ exhibits a reducing trend following $60 \mathrm{~mm}$ of displacement, which is indicative of the uplift failure process in the pipe sagging zone (i.e. reduced soil stiffness) as the point of contraflexure moves away from the displacement discontinuity, as shown in Figure 5. The position of peak strain in the sagging zone also moves away from the displacement discontinuity, and its magnitude remains relatively constant after stage 6 . The peak strains in the hogging zone remain in the same position and increase monotonically, indicating an elastic response, with the maximum measured on the invert.

Strains began to develop at the pipe end (Figure 5) after approximately $20 \mathrm{~mm}$ of displacement, which shows the progressive development of the pipe becoming endaffected at large displacements. Reduced stiffness of the surrounding soil due to mobilisation of post-peak resistance led to reduced end reactions, and hence the critical pipe length increased. This is the stiffest pipe (i.e. the one with the highest flexural rigidity in relation to longitudinal bending) to be tested in this differential ground motion simulation facility, with other tests (e.g. Ni et al. 2017) focussed on the measurement of pipe curvatures associated with longitudinal bending in the vicinity of a normal ground fault. Given the focus of the research reported here, that is pipe/soil interaction-generated AE, it was not necessary to ensure that zones near both ends of the pipe were free from curvature change.

Figure 7 shows the total station target array on the surface (photograph taken at the end of Test 1). Vertical surface movements of the sand parallel to the pipe on either side were greater than those measured directly above the pipe: point (d) moved vertically downwards by $25.6 \mathrm{~mm}$ more than point (c) in Test 1, and by $3.6 \mathrm{~mm}$ in Test 2, confirming the uplift failure mechanism took place. Sub-millimeter total vertical upwards movements were measured at points (a) and (b) in both tests indicating uplift; however, it should be noted that sub-millimeter measurements are at the limit of accuracy possible using a total station. 
Two visible shear bands, perpendicular to the displacement discontinuity and parallel to the pipe, emerge at the surface above the pipe in the sagging zone (separated by approximately $38 \mathrm{~cm}$ adjacent to the displacement discontinuity) in Test 1 (Figure 7), which resembles an inverted trapezoidal block and is characteristic of the uplift failure mechanism (Figure 2b). Uplift shear zones were not evident after Test 2. A shear zone above and parallel to the displacement discontinuity emerged at the soil surface in both tests.

\section{Interpretation of Acoustic Emission Measurements}

Figure 8 shows measurements obtained from AE system (1) in both tests and compares them to the measured vertical downwards displacement behavior of the pipe (plots for Test 1 and Test 2 are on the left and right, respectively).

Figures $8 \mathrm{c}$ to $8 \mathrm{f}$ show the total cumulative RDC generated by the end of stage 8 was 5.5 times greater in Test 2 than Test 1, reflecting the greater overburden (i.e. greater particleparticle and particle-pipe contact stresses) and the more concentrated shear zone. During periods where the moving floor was held stationary, negligible AE rates were generated, which can be seen in the AE rate time series (Figures $8 \mathrm{a}$ and $8 \mathrm{~b}$ ) and the horizontal steps in the cumulative AE time series (Figures $8 \mathrm{c}$ and $8 \mathrm{~d}$ ).

At the onset of displacement, the $A E$ rates rapidly increase and remain relatively constant at a peak value (proportional to the rate of imposed displacement) until displacement stops, whereupon they rapidly decrease and then gradually tail off due to continued but reducing rearrangement of particles at the pipe/soil interface. This response leads to cumulative AE time series' that are comparable to the pipe displacement time series (Figures 8c and 8d).

The inserts in Figures $8 \mathrm{e}$ and $8 \mathrm{f}$ show that $\mathrm{AE}$ activity began during stage 1 ; however, with significantly lower magnitude than in the later stages. This onset of $A E$ activity in stage 1 is indicative of the shear zone propagating from the floor to the pipe elevation.

A distinct transition in response takes place in the cumulative $A E$ vs. displacement relationships (Figures $8 \mathrm{e}$ and $8 \mathrm{f}$ ) where the $\mathrm{AE}$ generated in response to increments of displacement gradually increases until a certain 'threshold' magnitude of displacement, and then the AE activity increases linearly with further increments of displacement. This transition in behavior is sudden in Test 1 and occurs after stage 1. However, this process is more progressive in Test 2 and occurs over stages 3 to 6 .

This evolving behavior is exemplified in Figure 9, which shows the average RDC generated per $\mathrm{mm}$ of imposed displacement during each test stage. Relative pipe/soil deformation required to mobilise peak uplift resistance, $\Delta q_{\mathrm{u}}$, was calculated to be $12 \mathrm{~mm}$ (Table 3) for $0.6 \mathrm{~m}$ burial depth, and the sudden transition in behavior in Test 1 after stage 1 coincides with this. The RDC generated per $\mathrm{mm}$ of displacement then remains relatively constant.

Larger relative pipe/soil deformation is required to mobilise peak resistance with greater burial, and the value of $\Delta q_{u}$ calculated for Test 2 (1.2 m burial) was $24 \mathrm{~mm}$, which corresponds to stage 3 and the beginning of the progressive transition in $\mathrm{AE}$ response. The RDC generated per $\mathrm{mm}$ of displacement increases until stage 7 where it then remains relatively constant. The change in $\mathrm{AE}$ response is indicative of the evolution of the pipe/soil interaction process, where peak uplift resistance is progressively mobilised along the length of the pipe in the sagging zone. 
Linear regressions have been plotted through the $A E$ rate vs. displacement rate relationships in Figures $8 \mathrm{~g}$ and $8 \mathrm{~h}$ to quantify correlations $\left(\mathrm{R}^{2}\right.$ values ranging from 0.83 to 0.96). The finding that generated $A E$ rates are proportional to imposed displacement rates demonstrates the potential of the $\mathrm{AE}$ approach for detecting accelerating deformation behavior for use in early warning. The black regression lines (Test 1 excludes stage 1 and Test 2 excludes stages 1 to 4 ) represent the AE rate vs. displacement rate relationships after peak resistance has been mobilised. The gradient of the line for Test 2 is 8.7 times greater than the line for Test 1, showing that greater AE rates were generated in response to the same imposed rates of displacement due to the greater overburden and more concentrated shear strains.

Figure 10 shows time series of pipe displacement rate and $b$-value measured using $\mathrm{AE}$ system (2) and calculated using Equations 6 and 7 throughout Test 2 . The baseline $b-$ value is around 1.05 before the initiation of displacement in stage 1 . The $b$-value then gradually decreased (i.e. an increasing proportion of high magnitude events) with imposed displacement during stage 1 to a value of 0.83 after $4.6 \mathrm{~mm}(2.87 \mathrm{~min})$ before rapidly decreasing further to a value of 0.18 after $8.7 \mathrm{~mm}$ (4.6 min), and then increasing to 1.0-1.2 after movement stopped. The insert in Figure $8 f$ shows that $A E$ system (1) also began to detect elevated $\mathrm{AE}$ activity after approximately $4.6 \mathrm{~mm}$ of displacement, indicating the shear zone had propagated to the pipe elevation.

The $b$-value rapidly reduced after the onset of displacement in each subsequent test stage, reaching a minimum of 0.12 in stage $2,0.03$ in stage 3, 0.02 in stage 4, 0.01 in stage 5, and effectively zero thereafter. This pattern of gradually increasing proportion of higher magnitude AE events in each test stage is consistent with the evolution of the pipe/soil interaction failure process described earlier (e.g. Figure 9).

Following each stage after stage 4, the $b$-value gradually increased (i.e. the increase is no longer sudden) to a baseline level when displacement stopped, which is indicative of sustained pipe/soil interaction such as gap infilling beneath the pipe. Moreover, the baseline $b$-value that was reached after each test stage (i.e. during no floor movement) gradually decreased from 1.0-1.2 in the early test stages down to 0.7-0.8 in the latter stages, which is also indicative of sustained pipe/soil interaction activity, such as infilling and rearrangement of particles around the circumference of the pipe (i.e. flow-around mechanism).

\section{Discussion}

The results from the differential ground motion experiments performed on buried full-scale steel pipes instrumented with $\mathrm{AE}$ sensors have demonstrated that the pipe/soil interactiongenerated $A E$ is related to the stress level (i.e. particle-particle and particle-pipe contact stresses), bedding depth (i.e. shear zone width), the rate and magnitude of imposed deformation, and the evolution of the failure mechanism. The results demonstrate that $\mathrm{AE}$ can be used to detect, quantify and interpret accelerating differential ground motion deforming buried pipelines.

The interpretation of $A E$ measurements in this study has focused primarily on the evolution of the shear zone and uplift failure mechanism in the pipe sagging zone. Further research is required to isolate and investigate $A E$ generated by relative axial pipe/soil displacement. In addition, this study has focused on steel pipes with constant diameter; an increase in pipe diameter is expected to increase the measured $A E$ due to a greater circumference over which frictional interactions can take place. 
The magnitude of pipe/soil interaction-generated AE was significantly influenced by burial and bedding depth. Greater stress level led to larger particle-particle and particle-pipe contact stresses and a higher magnitude AE response. In addition, the localisation of shear strains in the shear zone disperse with elevation above the displacement discontinuity. The influence of stress level and shear zone thickness could not be investigated in isolation; however, it is expected that stress level was the primary contributor to increased AE activity because it acts over the entire surface area of the pipe, and previous studies (e.g. Koerner et al. 1984; Tanimoto and Tanaka 1986; Smith and Dixon 2015; Berg et al. 2018; Smith \& Dixon 2019) have demonstrated its significant influence on the magnitude of generated $A E$. It should also be noted that the difference in foundation depth (1.2 $\mathrm{m}$ in Test 1 and $0.5 \mathrm{~m}$ in Test 2$)$ would have resulted in a different bearing stiffness.

For an increase in burial depth of $100 \%(0.6 \mathrm{~m}$ to $1.2 \mathrm{~m})$, the gradient of the AE rate vs. displacement rate relationship increased by a factor of 8.7. Smith \& Dixon (2019) found that $A E$ generation in sands increases by a power law with stress level, but linearly with work done by boundary stresses (i.e. comprising elastic and plastic volumetric and distortional work).

Both the $b$-value and RDC approaches began to measure elevated AE activity during the first displacement increment as the shear zone intersected the pipe. Shear zone initiation at the base of the soil body was not detected because of the significant attenuation that the $A E$ experiences as it propagates in three dimensions through the soil mass. It is proposed that an AE monitoring system that combines both $b$-value and RDC measurement would enable detection of shear strains intersecting the pipe.

The RDC approach enables quantification of both the magnitude and rate of displacement. For example, RDC does not detect low magnitude $A E$ events that fall below the set threshold level and only measured AE during deformation (i.e. RDC is not influenced by background noise), which enables robust quantification of the deformation behaviour (i.e. magnitude and rate). In contrast, the $b$-value describes the proportion of low and high magnitude events and so includes all signals that the sensor detects within the frequency range, which means that baseline $b$-value readings would need to be established.

An example of how AE rate (RDC per unit time) measurements could be used to interpret accelerating deformation behavior is shown in Figure 11. Figure 11c illustrates how the current $A E$ rate $\left(A E_{t}\right)$ minus the preceding $A E$ rate $\left(A E_{t-1}\right)$ and normalised by the initial $A E$ rate measurement $\left(A E_{t=\xi}\right)$ provides the same relationship with deformation behaviour independent of stress level. It is important to note that stress level via burial depth remains relatively constant for each asset (i.e. the pipe depth rarely changes during asset life) but deformation behaviour evolves with time.

Warning criteria could comprise: (1) initiation of AE activity showing the onset of a shear zone intersecting the pipe; (2) transition in $A E$ behavior showing that post-peak soil uplift resistance has been mobilised; and (3) increasing $A E$ rates showing accelerating deformation behaviour (e.g. the insert in Figure 11c could be used to establish AE rate trigger levels based on changes in displacement rates). These could trigger engineers to inspect the asset and prioritise maintenance/remediation or terminate service to prevent catastrophic consequences, facilitating serviceability and ultimate limit state assessments.

Further research is required to investigate the influence of specific variables (e.g. soil properties, pipe diameter, shearing mechanism, relative axial pipe/soil displacement). However, the research reported here has demonstrated the potential for AE monitoring 
systems to detect and interpret pipe/soil interaction behavior to facilitate targeted and timely interventions. A field-viable monitoring system will also need to locate the position of distress along the pipeline to enable targeted, in addition to timely, interventions. Strategies that compute the arrival times of $\mathrm{AE}$ propagating in the pipe to sensor locations (e.g. Spriggs 2005; Heather-Smith et al. 2018) are in development and will allow the location of the source to be quantified.

\section{Conclusions}

This study has gone beyond the state-of-the-art and demonstrated that $A E$ can be used to detect, quantify and interpret accelerating differential ground motion deforming buried pipelines. Early warning of adverse behaviour will enable timely interventions. AE generated by pipe/soil interaction has been investigated for the first time in full-scale differential ground movement experiments. Tests on full-scale steel pipelines buried in dense sand and crossing a normal fault with different stress levels (via burial depth), bedding (foundation) depth and with varying rates of imposed deformation have led to the following principal findings:

- Measured AE was proportional to both the magnitude and rate of imposed displacement, and regressions for measured $A E$ vs. displacement and $A E$ rate vs. displacement rate relationships had strong correlations ( $R^{2}$ from 0.83 to 0.99$)$.

- The magnitude of pipe/soil interaction-generated AE was significantly influenced by stress level; for an increase in burial depth from 0.6 to $1.2 \mathrm{~m}$, the gradient of the $A E$ rate vs. displacement rate relationship increased by a factor of 8.7 .

- Patterns in AE (b-value and RDC) with time enabled interpretation of the evolution of the pipe/soil interaction mechanism; the onset of elevated $A E$ activity coincided with the shear zone intersecting the pipe elevation; and mobilised uplift resistance could be interpreted from the AE generated per $\mathrm{mm}$ vs. pipe displacement relationships.

- AE monitoring systems that combine measurement of $b$-values and RDC could alert decision makers of: (1) the onset of a shear zone intersecting the pipe; (2) mobilisation of peak soil resistance; and (3) accelerating deformation behaviour. These could trigger engineers to inspect the asset and prioritise maintenance/remediation or terminate service to prevent catastrophic consequences, facilitating serviceability and ultimate limit state assessments.

\section{Data Availability Statement}

Some or all data, models, or code generated or used during the study are available from the corresponding author by request (Displacement, Strain and Acoustic Emission measurements).

\section{Acknowledgements}

The authors acknowledge the excellent assistance in performing the split-box experiments provided by Graeme Boyd, Josh Coghlan, Brian Westervelt, Haitao Lan, Pengpeng Ni, Hendrik Williams, Anderson de Olivera and Gregor Browning. Alister Smith gratefully acknowledges the support of a UK Engineering and Physical Sciences Research Council Fellowship (Listening to Infrastructure, EP/P012493/1). The testing at Queen's was supported with funds to lan Moore through a Discovery Grant from the Natural Sciences and Engineering Research Council of Canada and Infrastructure Operating Funds from the Canada Foundation for Innovation. 


\section{Notation}

The following symbols are used in this paper:

$A=\mathrm{AE}$ waveform amplitude

$B=$ Bedding depth from soil base to spring line (i.e. foundation)

$b$-value $=$ Measure of the proportion of low and high magnitude events in an AE waveform

$\mathrm{C}_{\mathrm{u}}=$ Coefficient of uniformity

$\mathrm{C}_{\mathrm{c}}=$ Coefficient of curvature

$D_{r}=$ Relative density

$D_{o d}=$ Pipe outside diameter

$D_{i d}=$ Pipe internal diameter

$e_{\min }=$ Minimum void ratio

$e_{\max }=$ Maximum void ratio

$E_{\mathrm{p}}=$ Pipe elastic modulus

$f_{\mathrm{d}}=$ Uplift factor

$H=$ Burial depth from surface to pipe spring line

$I_{\mathrm{p}}=$ Pipe moment of inertia

$i_{\text {pipe }}, i_{\text {soil }}=$ Length scale from the location of peak curvature to the point of contraflexure for the pipe and soil deflection profile, respectively

$k_{\mathrm{u}}=$ Soil subgrade reaction stiffness

$I_{c}=$ Critical pipe length (Bransby et al. 2007) beyond which the pipe behaves as if it is infinitely long

$M=$ Log-scale measure of $\mathrm{AE}$ magnitude

$R D C=$ Ring-down counts are the number of times the $A E$ waveform crosses a voltage threshold level

$Q_{\mathrm{u}}=$ Peak soil resistance to vertical uplift

$\Delta q_{\mathrm{u}}, \Delta q_{d}=$ Relative pipe/soil deformation required to mobilise peak resistance in the vertical upwards and downwards direction, respectively

$V_{d}=$ Dry bulk unit weight of soil

$\rho_{\mathrm{s}}=$ Particle density

$\rho_{\mathrm{dry}_{\min }}=$ Minimum dry density

$\rho_{\text {dry }_{\text {max }}}=$ Maximum dry density

$\phi_{\mathrm{p}}^{\prime}=$ Peak effective friction angle

$\phi_{\text {crit }}^{\prime}=$ Constant volume friction angle 


\section{References}

Abdoun, T. H., Ha, D., O’Rourke, M. J., Symans, M. D., O’Rourke, T. D., Palmer, M. C., and Stewart, H. E. (2009). "Factors influencing the behavior of buried pipelines subjected to earthquake faulting". Soil Dynamics and Earthquake Engineering, 29(3), 415-427.

Anastasopoulos, I., Gazetas, G., Bransby, M. F., Davies, M. C. R., and El Nahas, A. (2007). "Fault rupture propagation through sand: finite-element analysis and validation through centrifuge experiments". Journal of Geotechnical and Geoenvironmental Engineering, 133(8), 943-958.

Berg, N., Smith, A., Russell, S., Dixon, N., Proudfoot, D., and Take, W. A. (2018). "Correlation of acoustic emissions with patterns of movement in an extremely slow moving landslide at Peace River, Alberta, Canada". Canadian Geotechnical Journal, (DOI: 10.1139/cgj-2016-0668).

Bransby, M. F., Nahas, E. L., Turner, E., and Davies, M. C. R. (2007). "The interaction of reverse faults with flexible continuous pipelines." International Journal of Physical Modelling in Geotechnics, 7(3), 25-40.

Cheuk, C. Y., White, D. J., and Bolton, M. D. (2008). "Uplift mechanisms of pipes buried in sand". Journal of Geotechnical and Geoenvironmental Engineering, 134(2), 154-163.

Dixon, N., Spriggs, M. P., Smith, A., Meldrum, P., and Haslam, E. (2015a). "Quantification of reactivated landslide behaviour using acoustic emission monitoring". Landslides, 12(3), 549-560.

Dixon, N., Smith, A., Spriggs, M., Ridley, A., Meldrum, P., and Haslam, E. (2015b). "Stability monitoring of a rail slope using acoustic emission". Proceedings of the Institution of Civil Engineers-Geotechnical Engineering, 168(5), 373-384.

Dixon, N., Smith, A., Flint, J. A., Khanna, R., Clark, B., and Andjelkovic, M. (2018). "An acoustic emission landslide early warning system for communities in low-income and middle-income countries". Landslides, (DOI: 10.1007/s10346-018-0977-1).

Garga, V. K., and Chichibu, A. (1990). "A study of AE parameters and shear strength of sand". Progress in Acoustic Emission, 129, 136.

Groves, J., and Wijewickreme, D. (2013). "Field monitoring of buried polyethylene natural gas pipelines subjected to ground movement". In GéoMontréal 2013, proceedings of the 66th Canadian geotechnical conference and the 11th joint CGS/IAH-CNC groundwater conference.

Heather-Smith, H. J., Smith. A., Dixon. N., Flint. J. A., and Wordingham. J. (2018). "Monitoring buried infrastructure deformation using acoustic emissions". 9th European Workshop on Structural Health Monitoring, July 10-13, 2018, Manchester, United Kingdom.

Karamitros, D. K., Bouckovalas, G. D., and Kouretzis, G. P. (2007). "Stress analysis of buried steel pipelines at strike-slip fault crossings". Soil Dynamics and Earthquake Engineering, 27(3), 200-211.

Koerner, R. M., Lord Jr, A. E., Mccabe, W. M., and Curran, J. W. (1976). "Acoustic emission behavior of granular soils". Journal of Geotechnical and Geoenvironmental Engineering, 102(ASCE\# 12239 Proceeding). 
Koerner, R. M., Lord Jr, A. E., and McCabe, W. M. (1978). "Acoustic emission monitoring of soil stability". Journal of Geotechnical and Geoenvironmental Engineering, 104(ASCE 13753).

Koerner, R. M., McCabe, W. M., \& Lord, A. E. (1981). "Acoustic emission behavior and monitoring of soils". In Acoustic emissions in geotechnical engineering practice. ASTM International.

Koerner, R. M., Lord Jr, A. E., and Deutsch, W. L. (1984). "Determination of prestress in granular soils using AE". Journal of Geotechnical Engineering, 110(3), 346-358.

Mao, W., Aoyama, S., Goto, S., and Towhata, I. (2015). "Acoustic emission characteristics of subsoil subjected to vertical pile loading in sand". Journal of Applied Geophysics, 119, 119-127.

Mao, W., Aoyama, S., Goto, S., and Towhata, I. (2016). "Behaviour and frequency characteristics of acoustic emissions from sandy ground under model pile penetration". Near Surface Geophysics, 14(6), 515-525.

Mao, W., Aoyama, S., and Towhata, I. (2018). "Feasibility study of using acoustic emission signals for investigation of pile spacing effect on group pile behaviour". Applied Acoustics, 139, 189-202.

Michlmayr, G., Chalari, A., Clarke, A., and Or, D. (2017). "Fiber-optic high-resolution acoustic emission (AE) monitoring of slope failure". Landslides, 14(3), 1139-1146.

Mitchell, R. J., and Romeril, P. M. (1984). "Acoustic emission distress monitoring in sensitive clay". Canadian Geotechnical Journal, 21(1), 176-180.

Ni, P., Moore, I. D., and Take, W. A. (2014). "Normal fault induced ground deformations and the associated bending response of buried pipelines". Second European Conference on Earthquake Engineering and Seismology, Istanbul, 25-29 August.

Ni, P., Moore, I. D., and Take, W. A. (2017). "Distributed fibre optic sensing of strains on buried full-scale PVC pipelines crossing a normal fault". Géotechnique, 68(1), 1-17.

Ni, P., Moore, I. D., and Take, W. A. (2018). "Numerical modeling of normal fault-pipeline interaction and comparison with centrifuge tests". Soil Dynamics and Earthquake Engineering, 105, 127-138.

Pollock, A. A. (1973). "Acoustic emission-2: acoustic emission amplitudes". Nondestructive testing, 6(5), 264-269.

Robert, D. J., Soga, K., and O'Rourke, T. D. (2016). "Pipelines subjected to fault movement in dry and unsaturated soils". International Journal of Geomechanics, 16(5), C4016001.

Saiyar, M., Ni, P., Take, W. A., and Moore, I. D. (2016). "Response of pipelines of differing flexural stiffness to normal faulting". Géotechnique, 66(4), 275-286.

Shiotani, T., and Ohtsu, M. (1999). "Prediction of slope failure based on AE activity". In Acoustic emission: standards and technology update. ASTM International.

Smith, A., Dixon, N., Meldrum, P., Haslam, E., and Chambers, J. (2014). "Acoustic emission monitoring of a soil slope: Comparisons with continuous deformation measurements". Géotechnique Letters, 4(4), 255-261. 
Smith, A., and Dixon, N. (2015). "Quantification of landslide velocity from active waveguide-generated acoustic emission”. Canadian Geotechnical Journal, 52(4), 413425.

Smith, A., Dixon, N. (2019) "Acoustic emission behaviour of dense sands". Géotechnique, 10.1680/jgeot.18.P.209

Smith, A., Dixon, N., and Fowmes, G. (2017a). "Early detection of first-time slope failures using acoustic emission measurements: large-scale physical modelling". Géotechnique, 67(2), 138-152.

Smith, A., Dixon, N., and Fowmes, G. (2017b). "Monitoring buried pipe deformation using acoustic emission: quantification of attenuation". International Journal of Geotechnical Engineering, 11(4), 418-430.

Spriggs, M. (2005). "Quantification of acoustic emission from soils for predicting landslide failure". Ph.D. thesis. School of Architecture, Building and Civil Engineering, Loughborough University, UK.

Tanimoto, K., and Tanaka, Y. (1986). "Yielding of soil as determined by acoustic emission". Soils and foundations, 26(3), 69-80.

Tognon, A. R., Rowe, R. K., and Brachman, R. W. (1999). "Evaluation of side wall friction for a buried pipe testing facility". Geotextiles and Geomembranes, 17(4), 193-212.

Vazouras, P., Dakoulas, P., and Karamanos, S. A. (2015). "Pipe-soil interaction and pipeline performance under strike-slip fault movements". Soil Dynamics and Earthquake Engineering, 72, 48-65. 


\section{Tables}

Table 1. Average displacement rates applied in each test stage

\begin{tabular}{|c|c|c|}
\hline \multirow[b]{2}{*}{ Stage } & \multicolumn{2}{|c|}{ Displacement rate $(\mathrm{mm} / \mathrm{min})$} \\
\hline & Test $1^{a}$ & Test $2^{b}$ \\
\hline 1 & 1.93 & 2.06 \\
\hline 2 & 2.37 & 2.32 \\
\hline 3 & 4.39 & 3.51 \\
\hline 4 & 3.97 & 3.90 \\
\hline 5 & 3.36 & 3.05 \\
\hline 6 & 6.45 & 5.26 \\
\hline 7 & 6.54 & 8.45 \\
\hline 8 & 8.55 & 3.70 \\
\hline 9 & - & 3.59 \\
\hline 10 & - & 3.51 \\
\hline
\end{tabular}

Note: The total displacement in each stage was $10 \mathrm{~mm}$.

a Test 1 had a burial depth of $0.6 \mathrm{~m}$ (1.2m bedding depth) to the spring line and a total displacement of $80 \mathrm{~mm}$.

b Test 2 had a burial depth of $1.2 \mathrm{~m}(0.5 \mathrm{~m}$ bedding depth) to the spring line and a total displacement of $100 \mathrm{~mm}$.

Table 2. Properties of the synthetic olivine sand (Ni et al. 2017)

\begin{tabular}{|c|c|c|c|c|c|c|c|c|c|c|c|c|}
\hline $\begin{array}{c}d_{10} \\
(\mathrm{~mm})\end{array}$ & $\underset{(\mathrm{mm})}{d_{50}}$ & $\mathrm{C}_{\mathrm{u}}$ & $C_{c}$ & $\begin{array}{c}\rho_{\mathrm{s}} \\
\left(\mathrm{Mg} / \mathrm{m}^{3}\right)\end{array}$ & $\begin{array}{c}\rho_{\mathrm{dry}_{\min }} \\
\left(\mathrm{Mg} / \mathrm{m}^{3}\right)\end{array}$ & $\begin{array}{c}\rho_{\mathrm{dry}_{\max }} \\
\left(\mathrm{Mg} / \mathrm{m}^{3}\right)\end{array}$ & $\mathbf{e}_{\min }$ & $\mathbf{e}_{\max }$ & $\begin{array}{c}\text { Mohs } \\
\text { Hardness }\end{array}$ & $\phi_{p}^{\prime}$ & $\phi_{\text {crit }}^{\prime}$ & Shape \\
\hline 0.46 & 0.83 & 2.21 & 0.96 & 3.2 & 1.5 & 1.7 & 0.88 & 1.13 & $6.5-7.0$ & $42^{\circ}$ & $34^{\circ}$ & $\begin{array}{l}\text { Subangular } \\
\text { to angular }\end{array}$ \\
\hline
\end{tabular}

Table 3. Pipe, soil and pipe/soil interaction parameters computed for the two burial depths

\begin{tabular}{|c|c|c|c|c|c|c|c|c|c|c|}
\hline $\begin{array}{c}H \\
(\mathrm{~m})\end{array}$ & $D_{\text {od }}(\mathrm{m})$ & $D_{\mathrm{id}}(\mathrm{m})$ & $f_{\mathrm{d}}$ & $\begin{array}{c}Y_{\mathrm{d}} \\
\left(\mathrm{kN} / \mathrm{m}^{3}\right)\end{array}$ & $E_{\mathrm{p}}(\mathrm{kPa})$ & $I_{\mathrm{p}}\left(\mathrm{m}^{4}\right)$ & $\begin{array}{c}Q_{\mathrm{u}} \\
\left(k N / \mathrm{m}^{2}\right)\end{array}$ & $\begin{array}{l}\Delta q_{\mathrm{u}} \\
(\mathrm{m})\end{array}$ & $\begin{array}{c}k_{\mathrm{u}} \\
\left(k N / \mathrm{m}^{3}\right)\end{array}$ & $I_{c}(\mathrm{~m})$ \\
\hline 0.6 & 0.167 & 0.158 & 1 & 16.42 & $2 \times 10^{8}$ & $7.59 \times 10^{-6}$ & 45.2 & 0.012 & 3770.7 & 3.18 \\
\hline 1.2 & 0.167 & 0.158 & 1 & 16.42 & $2 \times 10^{8}$ & $7.59 \times 10^{-6}$ & 161.3 & 0.024 & 6720.4 & 2.76 \\
\hline
\end{tabular}

Note: $f_{\mathrm{d}}=1.0$ for dense sand (Bransby et al., 2007) 


\section{Figures}
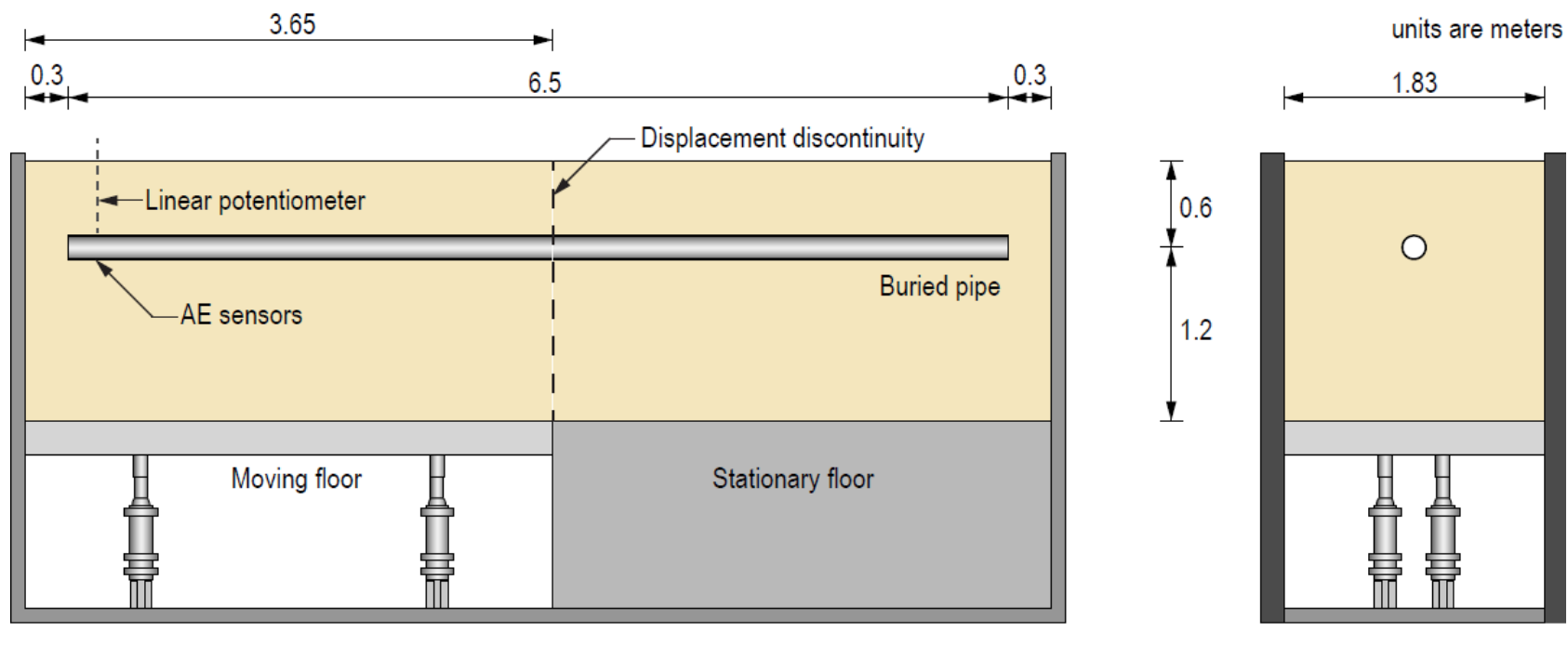

(a)

Side view

(b) Cross-section view

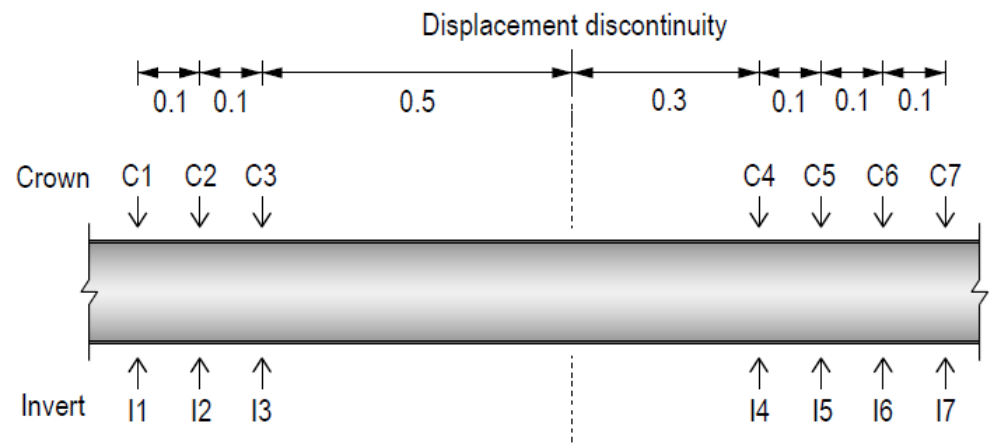

(c)

(d)

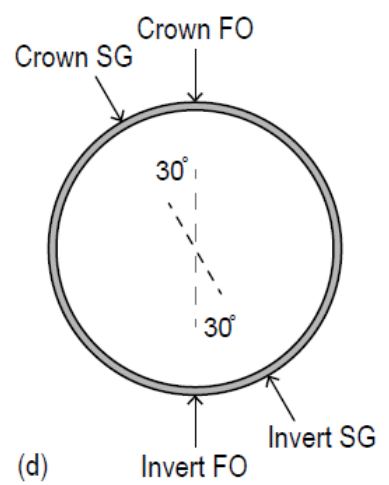

Figure 1. (a) and (b) show cross-sections of the differential ground movement apparatus with a pipe burial depth of $0.6 \mathrm{~m}$. (c) shows the locations of the strain gauge (SG) installations on the crown and invert for Test 1 (positions 1, 2 and 3 are on the moving side). (d) shows the SG and fibre optic (FO) installations used in Test 2 (the SGs were rotated $30^{\circ}$ to enable installation of $\mathrm{FO}$ cables along the crown and invert). Units are meters
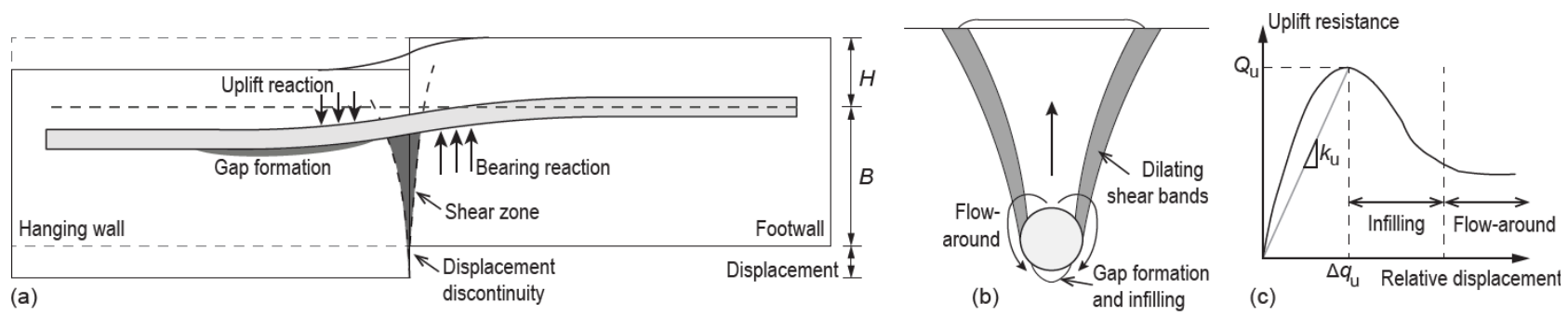

Figure 2. (a) Illustration of the differential ground motion simulator showing an example pipe deflection profile, shear zone, bearing and uplift reactions, and gap formation. (b) Illustration of the uplift failure mechanism. (c) Illustration of uplift load-displacement response 


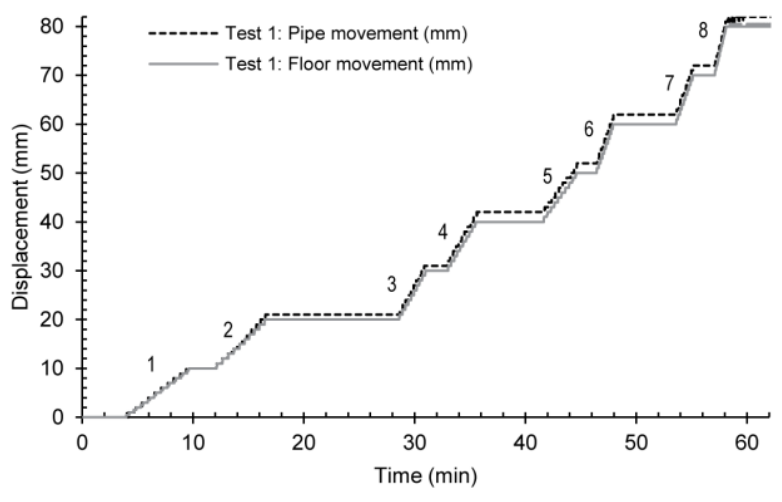

(a)

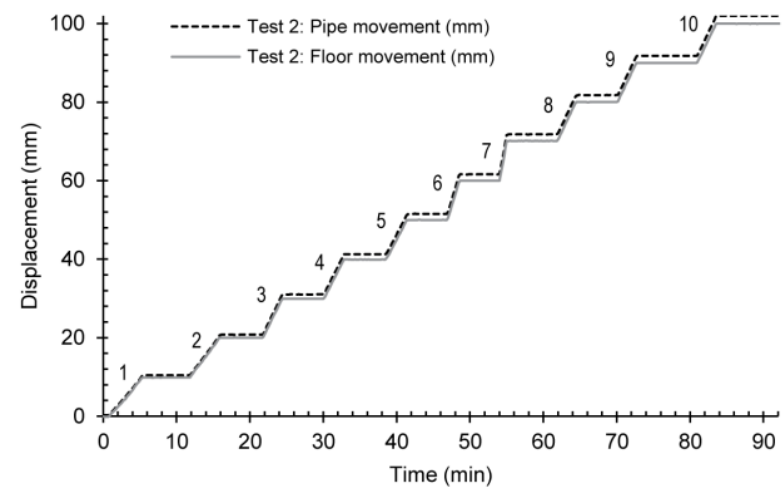

(b)

Figure 3. Vertical downwards displacement vs. time measured by the linear (string) potentiometers connected to the moving floor and pipe $(20 \mathrm{~cm}$ from the pipe end on the moving side). (a) Test 1 and (b) Test 2. Each test stage is numbered



Figure 4. Longitudinal strain (\%) measured by the SGs on the crown and invert during Test 1. Note that positive strain is tensile 


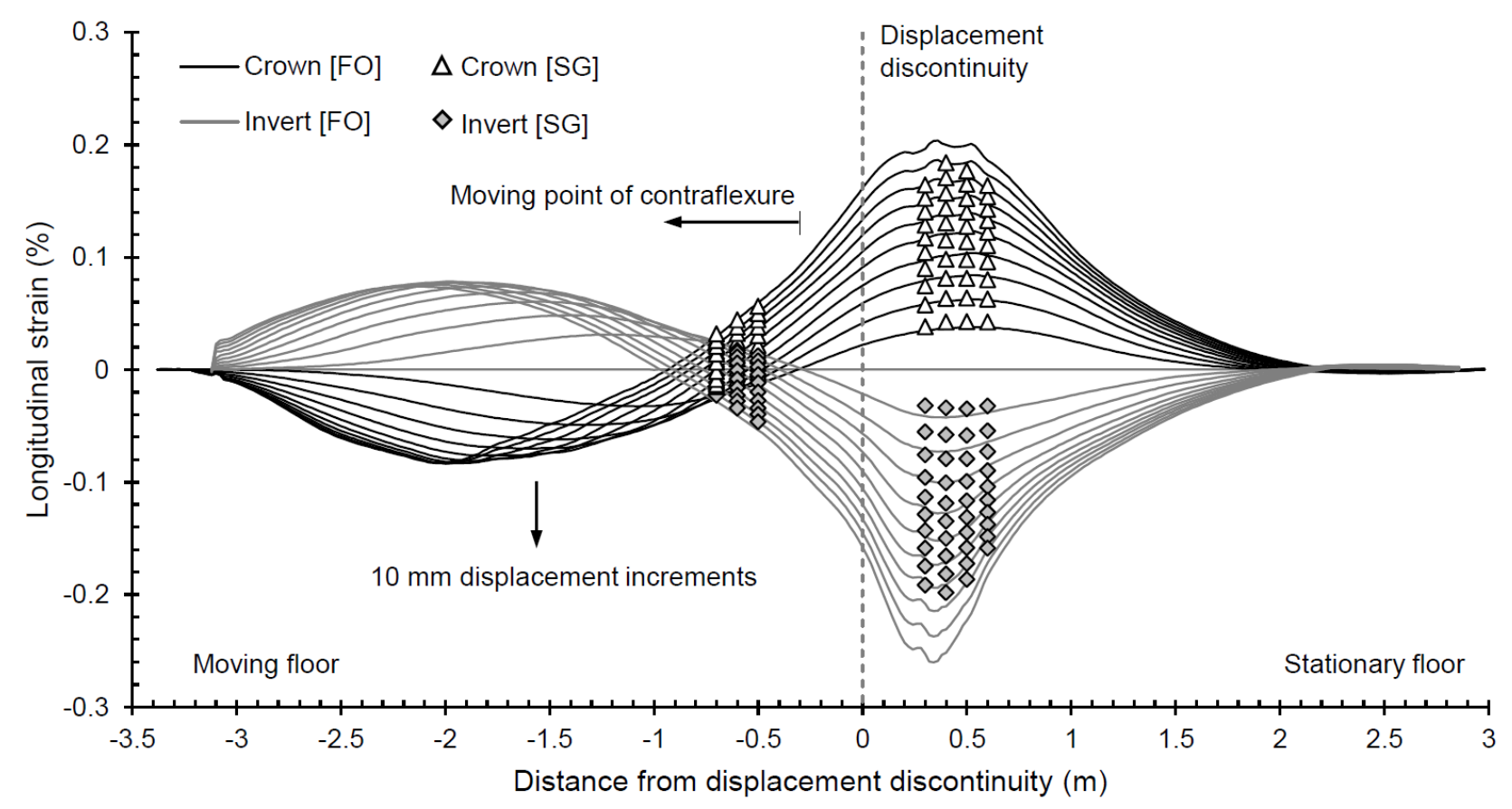

Figure 5. Longitudinal strain (\%) measured by the FO cables and SGs along the crown and invert during Test 2 after each $10 \mathrm{~mm}$ displacement increment. Note the SGs were offset from the crown and invert by $30^{\circ}$

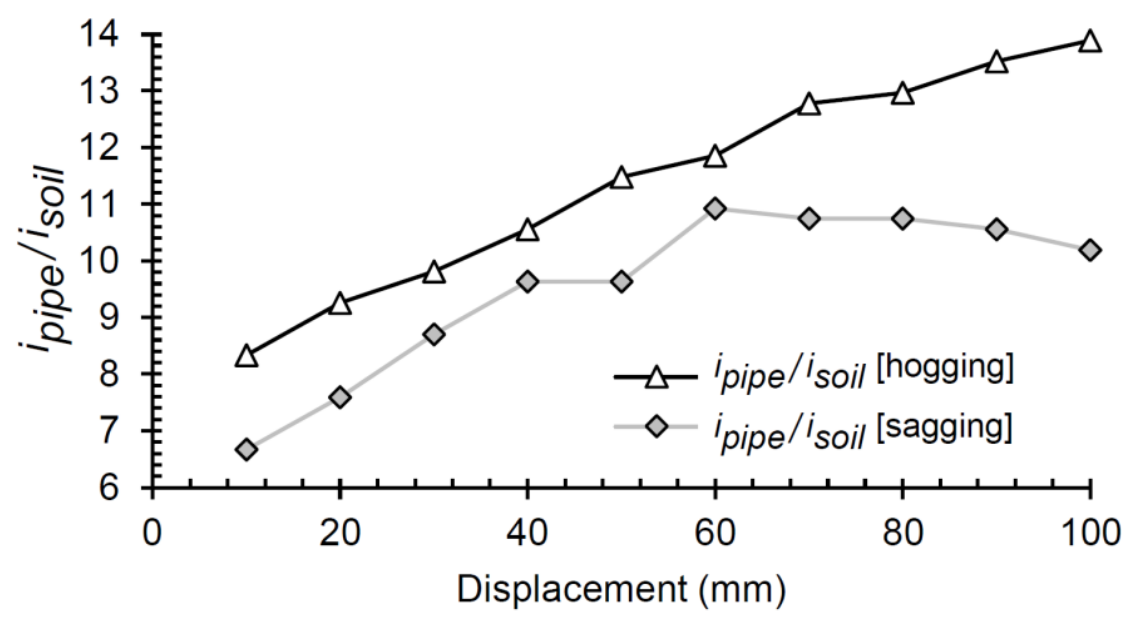

Figure 6 . Ratio of $i_{\text {pipe }}$ to $i_{\text {soil }}$ for hogging and sagging zones plotted against displacement for Test 2 


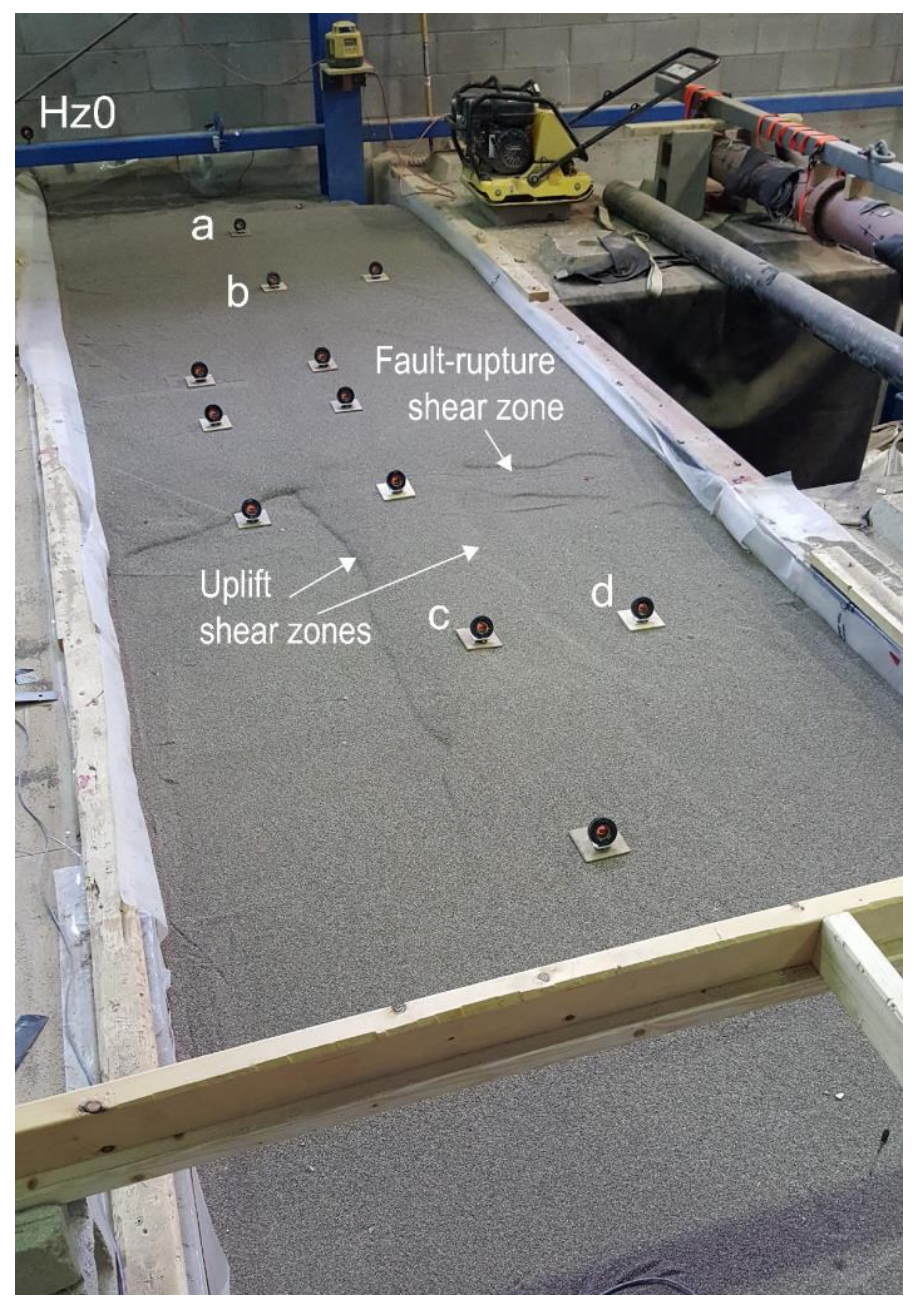

Figure 7. Photograph of the soil surface at the end of Test 1. Highlighted are the horizontal zero $(\mathrm{HzO})$ reference and four targets $(\mathrm{a}, \mathrm{b}, \mathrm{c}$ and $\mathrm{d})$ referred to in the main text 

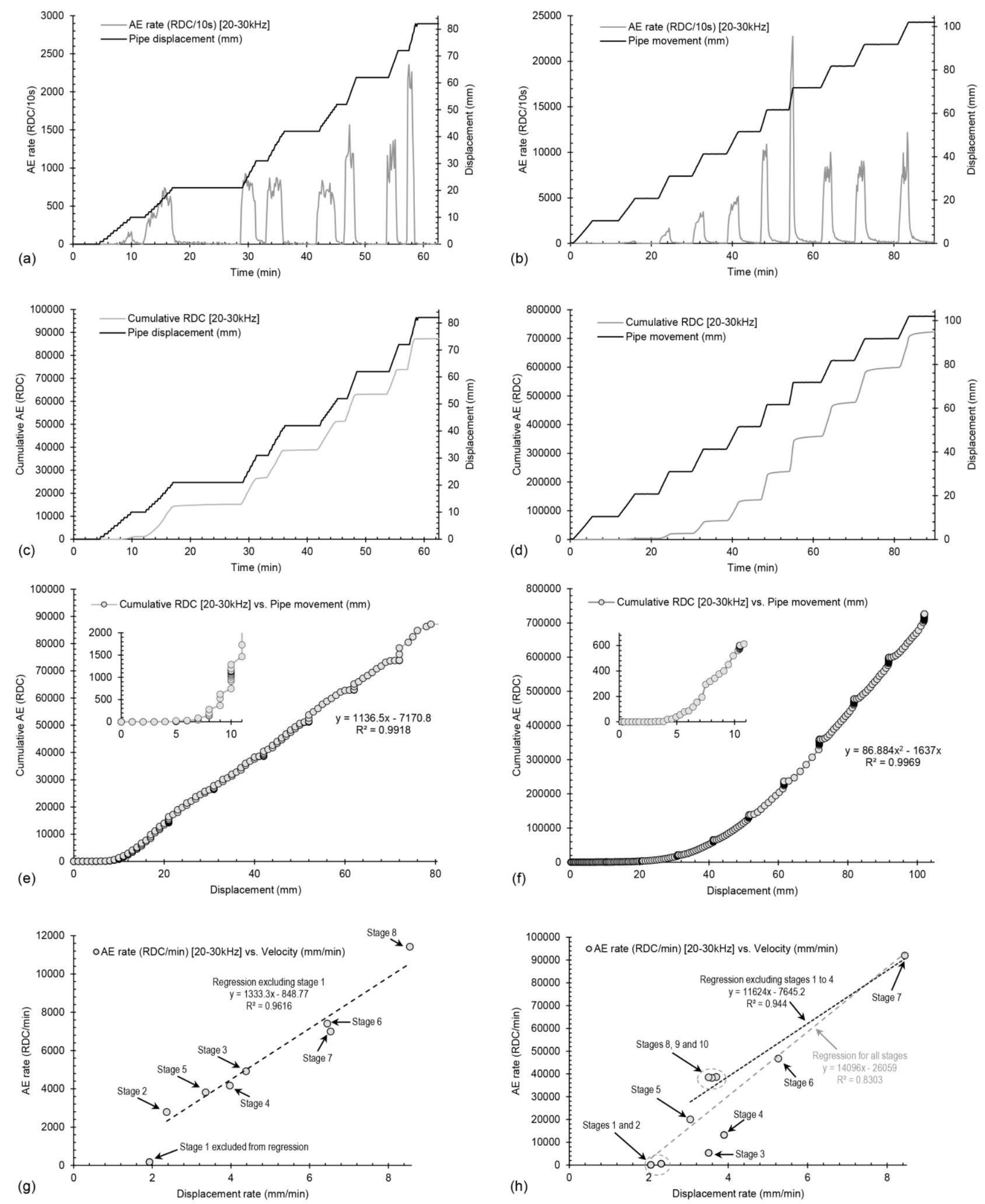

Figure 8. AE rate (RDC/10s) and vertical downwards pipe displacement (measured $20 \mathrm{~cm}$ from the pipe end on the moving floor) time series for Test 1 (a) and Test 2 (b). Cumulative $\mathrm{AE}(\mathrm{RDC})$ and vertical downwards pipe displacement time series for Test 1 (c) and Test 2 (d). Cumulative RDC vs. vertical downwards pipe displacement relationships from Test 1 (e) and Test 2 (f). AE rate (RDC/min) vs. vertical downwards pipe displacement rate $(\mathrm{mm} / \mathrm{min})$ relationships (points represent average values for each test stage) from Test 1 (g) and Test 2 (h) 


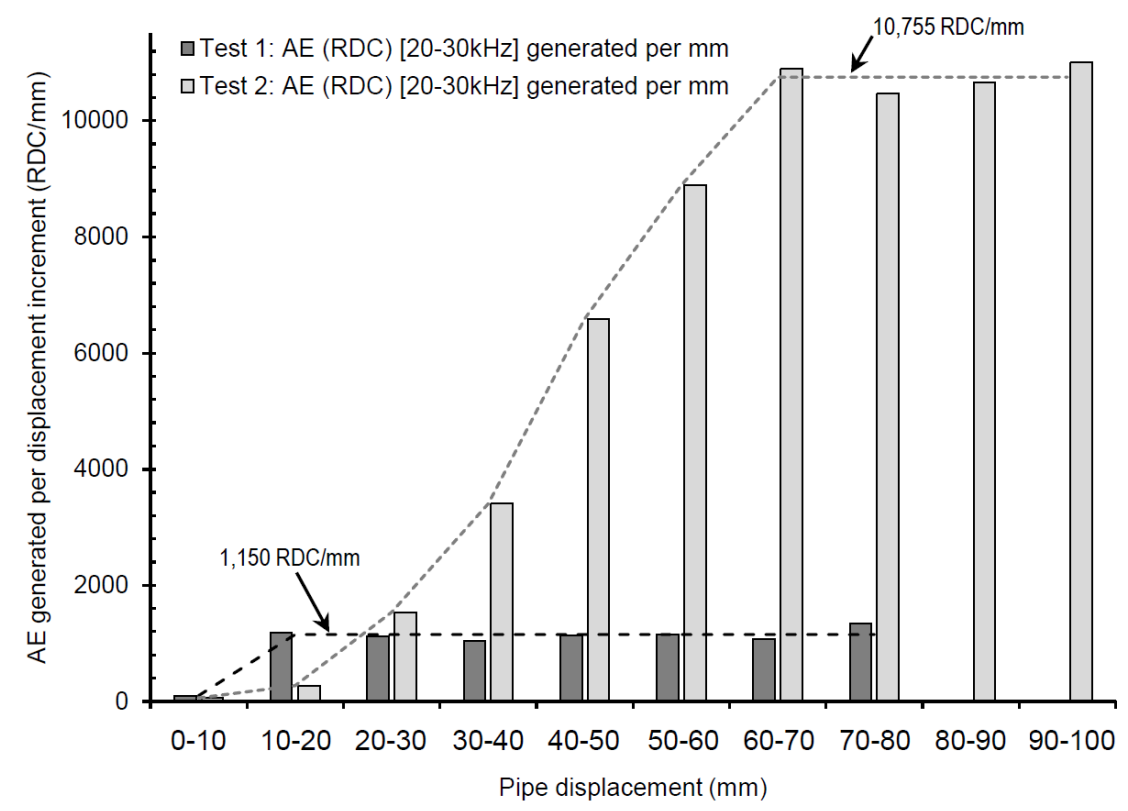

Figure 9. $A E(R D C)$ generated per $\mathrm{mm}$ of imposed displacement in each test stage (i.e. 10 $\mathrm{mm}$ displacement increments) for both Test 1 and Test 2

(a)
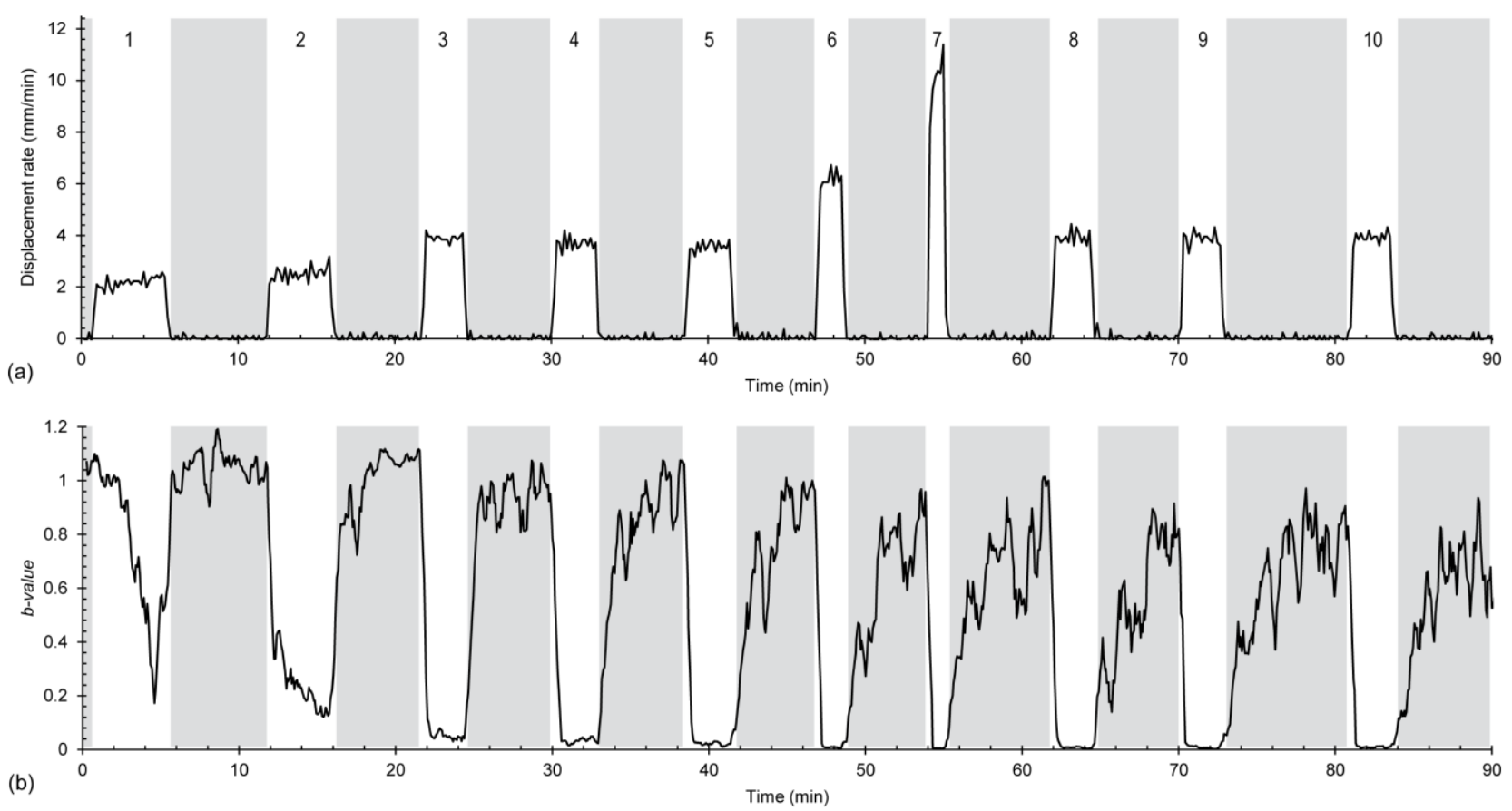

Figure 10. Test 2 time series of vertical downwards pipe displacement rate $(\mathrm{mm} / \mathrm{min})(\mathrm{a})$ and $b$-values obtained within the frequency range of $10-100 \mathrm{kHz}(\mathrm{b})$. The shaded periods show when no movement was taking place 
(a)

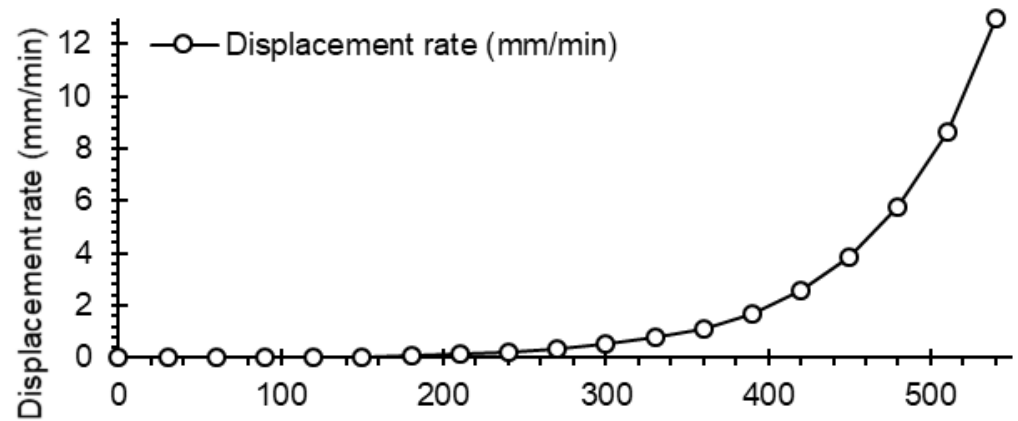

Time (minutes)
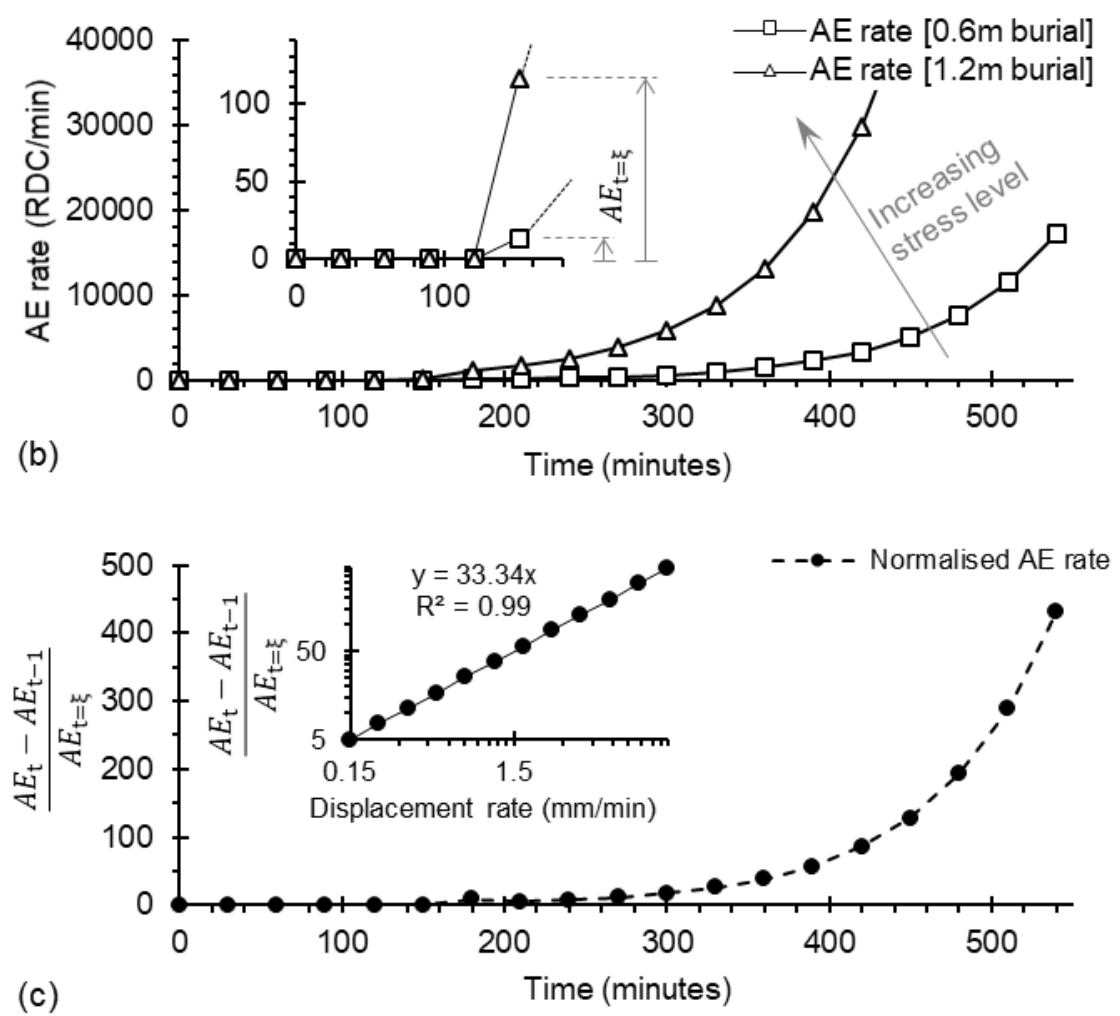

Figure 11. Example use of $A E$ for interpreting accelerating pipe/soil deformation behaviour. The example uses the AE rate versus pipe displacement rate relationships in Figures $8 \mathrm{~g}$ and $8 \mathrm{~h}$. (a) Displacement rate versus time for an illustrative progressive failure event, (b) $A E$ rate versus time for 0.6 and $1.2 \mathrm{~m}$ burial depths, and (c) normalised $A E$ rate versus time and the insert shows normalised $A E$ rate versus displacement rate 